\title{
Undiagnosed malignant hypertension presenting as a direct spontaneous carotid-cavernous fistula with complete loss of vision and hyphaema
}

\author{
Vinita Gupta 이 , ${ }^{1}$ Saurabh Luthra, ${ }^{2}$ Athul Suresh Puthalath 지 , ${ }^{1}$ Udit Chauhan ${ }^{1}$
}

'Department of Ophthalmology, AllMS Rishikesh, Rishikesh, India ${ }^{2}$ Department of Ophthalmology, Drishti Eye Institute, Dehradun, India

Correspondence to

Dr Vinita Gupta:

drvinitagupta@hotmail.com

Accepted 7 November 2021

\section{DESCRIPTION}

A 60-year-old woman presented with complete loss of vision in the right eye (RE) with progressive protrusion and complete drooping of the right eyelid since 1 week (figure 1A,B). There was no history of trauma and patient was not on any systemic medications. Ocular examination revealed tense swelling of the eyelid with $6 \mathrm{~mm}$ axial non-pulsatile proptosis with an audible bruit in the RE along with total external ophthalmoplegia and severe chemosis. There was no perception of light in the RE. There was total hyphaema precluding view of intraocular details. Intraocular pressure (IOP) was elevated to $38 \mathrm{~mm} \mathrm{Hg}$. The left eye had best corrected visual acuity of $6 / 6$ with a normal anterior segment. However, malignant hypertensive retinopathy changes were seen on posterior segment examination in the left eye (figure 1C-E). On systemic examination, she had elevated blood pressure of 220/130 mm Hg; however, she was not a diagnosed case of hypertension.

Ocular hypotensive treatment was initiated to control raised IOP and patient was referred for emergency medical management of her elevated blood pressure. On investigative work-up of the patient, no abnormality was detected in haemogram, peripheral smear examination, blood glucose and glycosylated haemoglobin levels, thyroid profile, liver function tests and lipid profile. Evaluation of her renal functions revealed normal serum creatinine, normal blood urea nitrogen, no abnormality on urinalysis and an unremarkable abdominal sonography. Her chest radiography was also normal. Her electrocardiography showed mild left ventricular hypertrophy. Patient was diagnosed to be in malignant phase hypertension and medical management for the same was initiated. Subsequent contrast enhanced CT (CECT) of brain and orbits revealed an enlarged right cavernous sinus with convexity of the lateral wall (figure 2A,B). Superior ophthalmic vein on right side was tortuous and dilated with early opacification on contrast along with thickened and bulky extraocular muscles (figure 2C,D). Based on these CECT findings corroborative of right direct carotid-cavernous fistula (CCF), patient was referred to neurosurgery for further management.

Direct CCFs are most commonly seen in young men and are due to trauma. However, they may also be caused by rupture of an internal carotid artery (ICA) aneurysm inside the cavernous sinus, Ehlers-Danlos type 4 or iatrogenic intervention. ${ }^{12}$ Indirect CCFs are usually seen in elderly hypertensive atherosclerotic patients. ${ }^{1}$ Rarely, a direct CCF can also be caused by rupture of an undiagnosed ICA aneurysm during hypertensive spikes in the elderly post menopausal women. ${ }^{3}$ Aneurysmal ruptures in these cases occur because of weakening of the aneurysmal wall by direct
Check for updates

(C) BMJ Publishing Group Limited 2022. No commercial re-use. See rights and permissions. Published by BMJ.

To cite: Gupta V, Luthra S, Puthalath AS, et al. BMJ Case Rep 2022;15:e246243. doi:10.1136/bcr-2021246243
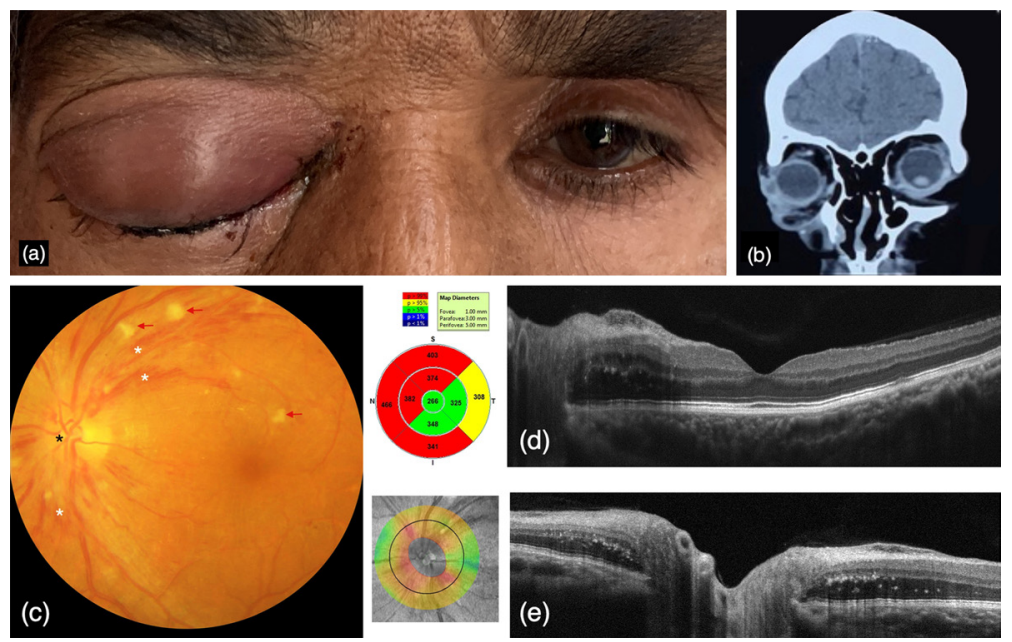

Figure 1 (A) Clinical photograph showing protrusion of the right eye with complete ptosis. (B) Contrast enhanced CT orbit coronal section showing proptosis of right eye with preseptal oedema with prominent superior ophthalmic vein on right side. (C) Fundus photograph of left eye showing malignant hypertensive retinopathy changes disc oedema (black star), flame shaped haemorrhages (white stars) and cotton wool spots (red arrows). (D) Optical coherence tomography (OCT) macula (macular thickness map and transverse structural B-scan) of the left eye showing retinal oedema in temporal juxta papillary region with normal central macular thickness. (E) OCT optic nerve head (RNFL thickness map and transverse structural B-scan) showing optic nerve head oedema and peripapillary oedema. 


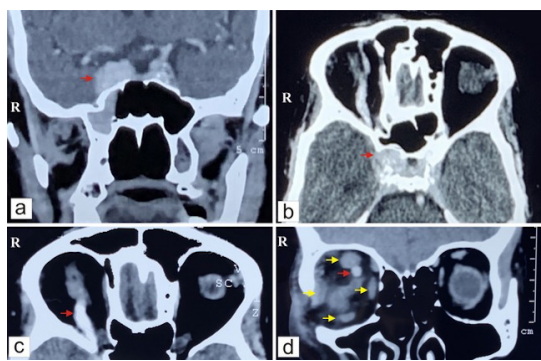

Figure 2 Contrast enhanced CT of orbit and brain findings consistent with right carotid-cavernous fistula (A) coronal section base of skull and (B) axial section base of skull-showing dilated right cavernous sinus with intense enhancement with convexity of the lateral wall (red arrow). (C) Axial section orbit showing dilated right superior ophthalmic vein (red arrow). (D) Coronal section orbit showing dilated right superior ophthalmic vein (red arrow) and bulky and oedematous extra ocular muscles on right side (yellow arrows).

increase in the mechanical stress. In addition, systemic hypertension can cause activation of local renin-angiotensin system leading to vascular inflammation and remodelling, and indirectly contributing to the rupture. ${ }^{4}$

Ophthalmic findings in CCF include proptosis, ocular bruit, eyelid swelling, ptosis, chemosis, arterialised conjunctival vessels, motility disturbances, decreased visual acuity, glaucoma, stasis retinopathy, central retinal vein occlusion, retinal ischemia, retinal artery occlusion and optic disc swelling. ${ }^{3}$ Visual loss may be secondary to corneal, retinal or optic nerve changes or may result from the accompanying glaucoma. Immediate visual loss in high flow direct CCF can be due to intraocular haemorrhage, central retinal artery occlusion (CRAO), traumatic optic neuropathy and posterior ischaemic optic neuropathy. ${ }^{6-8}$ Evaluation of a suspected CCF often involves noninvasive neuroimaging techniques which demonstrate a prominent SOV. $^{29}$ However, digital subtraction angiography remains the gold standard if endovascular embolisation is contemplated. ${ }^{2} 10$

Our patient presented with total hyphaema with complete loss of vision as the presenting feature and was diagnosed as a case of direct spontaneous CCF with malignant phase hypertension based on clinical features and imaging. To the best of our knowledge ours is a first case of direct spontaneous CCF presenting with complete

\section{Learning points}

Spontaneous direct carotid-cavernous fistulas (CCFs) are extremely rare but potentially devastating cause of ocular symptoms, visual loss and periocular morbidity. They are usually caused by rupture of the intracavernous internal carotid artery aneurysms, which may occur during hypertensive spikes in elderly atherosclerotic women.

- A high index of suspicion of a direct spontaneous CCF should be kept in mind when a patient presents with rapidly progressive proptosis with severe visual loss even in the absence of trauma, connective tissue disorder or any preexisting systemic disease.

- CCF patients may initially present to an ophthalmologist who should make a presumptive diagnosis, advice appropriate imaging studies and refer for timely neurosurgical intervention. loss of vision with total hyphaema as the presenting feature. Oono et al have reported massive hyphaema in a case of spontaneous Barrow type C CCF. ${ }^{11}$ However, hyphaema in their case occurred following stereotactic radiosurgery which was necessitated 5 months after intervention with transcatheter arterial embolisation. Hyphaema in our case could be explained by the probable development of neovascularisation of the iris which can occur as early as 1 week following CRAO and Ophthalmic artery occlusions, the incidence and the rapidity of the onset of which is related to the level of overall ocular and retinal ischaemia. ${ }^{12}$

Twitter Athul Suresh Puthalath @asputhalath

Acknowledgements We acknowledge help of Dr Shrey Maheshwari in editing of images.

Contributors VG: Substantial contributions to the conception or design of the work; or the acquisition, analysis, or interpretation of data for the work, and drafting the work or revising it critically for important intellectual content and final approval of the version to be published. SL: Substantial contributions to the conception or design of the work; or the acquisition, analysis, or interpretation of data for the work, and drafting the work or revising it critically for important intellectual content and final approval of the version to be published. AP: Substantial contributions to the conception or design of the work; or the acquisition, analysis, or interpretation of data for the work, and drafting the work or revising it critically for important intellectual content and final approval of the version to be published. UC: Substantial contributions to the conception or design of the work; or the acquisition, analysis, or interpretation of data for the work and final approval of the version to be published.

Funding The authors have not declared a specific grant for this research from any funding agency in the public, commercial or not-for-profit sectors.

Competing interests None declared.

Patient consent for publication Consent obtained directly from patient(s).

Provenance and peer review Not commissioned; externally peer reviewed.

Case reports provide a valuable learning resource for the scientific community and can indicate areas of interest for future research. They should not be used in isolation to guide treatment choices or public health policy.

\section{ORCID iDs}

Vinita Gupta http://orcid.org/0000-0002-7118-2329

Athul Suresh Puthalath http://orcid.org/0000-0002-0483-7014

\section{REFERENCES}

1 Barrow DL, Spector RH, Braun IF, et al. Classification and treatment of spontaneous carotid-cavernous sinus fistulas. J Neurosurg 1985;62:248-56.

2 Henderson AD, Miller NR. Carotid-Cavernous fistula: current concepts in aetiology, investigation, and management. Eye 2018:32:164-72.

3 Chaudhry IA, Elkhamry SM, Al-Rashed W, et al. Carotid cavernous fistula: ophthalmological implications. Middle East Afr J Ophthalmol 2009;16:57-63.

4 Tada Y, Wada K, Shimada K, et al. Roles of hypertension in the rupture of intracranial aneurysms. Stroke 2014;45:579-86.

5 de Keizer R. Carotid-Cavernous and orbital arteriovenous fistulas: ocular features, diagnostic and hemodynamic considerations in relation to visual impairment and morbidity. Orbit 2003;22:121-42.

6 Alam MS, Jain M, Mukherjee B, et al. Visual impairment in high flow and low flow carotid cavernous fistula. Sci Rep 2019:9:12872.

7 Oh DJ, Chhadva P, Kanu LN. Sudden-onset blindness from a spontaneous carotidcavernous fistula with secondary central retinal artery occlusion and posterior ischemic optic neuropathy. Neuroophthalmology 2019;43:107-13.

8 Razeghinejad M-R, Tehrani MJ. Sudden onset and blinding spontaneous direct carotidcavernous fistula. J Ophthalmic Vis Res 2011;6:50-3.

9 Adam CR, Shields CL, Gutman J, et al. Dilated superior ophthalmic vein: clinical and radiographic features of 113 cases. Ophthalmic Plast Reconstr Surg 2018;34:68-73.

10 Chen C-J, Mastorakos P, Caruso JP, et al. Transorbital approach for endovascular occlusion of carotid-cavernous fistulas: technical note and review of the literature. Cureus 2017;9:e976.

11 Oono Y, Miyoshi M, Yoshimura K, et al. Massive hyphaema with poor visual outcome in a case of spontaneous carotid cavernous sinus fistula. Rinsho Ganka 2005:59:1381-4

12 Flaxel CJ, Adelman RA, Bailey ST. Retinal and ophthalmic artery occlusions preferred practice Pattern®. Ophthalmology 2020;127:P259-87. 
Copyright 2022 BMJ Publishing Group. All rights reserved. For permission to reuse any of this content visit https://www.bmj.com/company/products-services/rights-and-licensing/permissions/

BMJ Case Report Fellows may re-use this article for personal use and teaching without any further permission.

Become a Fellow of BMJ Case Reports today and you can:

- Submit as many cases as you like

- Enjoy fast sympathetic peer review and rapid publication of accepted articles

Access all the published articles

Re-use any of the published material for personal use and teaching without further permission

Customer Service

If you have any further queries about your subscription, please contact our customer services team on +44 (0) 2071111105 or via email at support@bmj.com.

Visit casereports.bmj.com for more articles like this and to become a Fellow 